\title{
Steps Toward Understanding the Inheritance of Repressive Methyl-Lysine Marks in Histones
}

\author{
D. Reinberg, ${ }^{*}$ S. Chuikov, ${ }^{*}$ P. FArnham ${ }^{\dagger}$ D. KarachentSeV ${ }^{\ddagger}$, A. Kirmizis ${ }^{\dagger}$, \\ A. Kuzmichev, ${ }^{*}$ R. Margueron, ${ }^{*}$ K. Nishioka, ${ }^{*}$ T.S. Preissner, ${ }^{*}$, K. Sarma, \\ C. Abate-Shen, $"$ R. STeward, ${ }^{\ddagger}$ AND A. VAqUero* \\ "Howard Hughes Medical Institute, Division of Nucleic Acids Enzymology, Department of Biochemistry, Robert \\ Wood Johnson Medical School, Piscataway, New Jersey 08854; ${ }^{\dagger}$ UC Davis Genome Center and Biomedical \\ Sciences Facility, Davis, California 95616-8816; "Waksman Institute, Rutgers University, Piscataway, New Jersey \\ 08854; ${ }^{\&} X$ Inactivation Group, MRC Clinical Sciences Centre, ICSM, Hammersmith Hospital, London W12 0NN, \\ United Kingdom; "Center for Advanced Biotechnology and Medicine, Department of Medicine and Cancer \\ Institute of New Jersey, Robert Wood Johnson Medical School, Piscataway, New Jersey 08854
}

The establishment of cellular identity in multicellular organisms proceeds according to a pattern of gene expression that is adjusted temporally and spatially. It has become evident that changes within the chromatin structure brought about by covalent modifications of histones are of crucial importance in this as well as in many other biological processes.

A focus of our studies involves the identity and functional roles of the cellular proteins that enable the transcriptional machinery to access and move through the nucleosomal DNA. This entails alterations within the nucleosomal structure. To get to this stage, the overall chromatin structure must unfold. Our recent studies have focused on the properties of the nucleosomal proteins that are determinant to the overall organization of compacted chromatin. It is these proteins that proscribe or enable DNA accessibility. The complex chromosome structure around silent genes is tightly wound (heterochromatin) prohibiting access to the transcriptional machinery, while it is more loosely wrapped around the genes active in RNA synthesis (euchromatin). Over the past few years, researchers have uncovered that the key to these two different chromatin structures resides in the histone tails that embody unstructured, hooklike projections extending outward from each nucleosome. Posttranslational modifications in these histone tails determine whether they lock together tightly or loosely and thus whether the genes spooled around them are silent or active.

Several discoveries in 1996 heralded a momentous year for members of the transcription and chromatin communities. Two reports provided the long awaited connection between chromatin and the regulation of gene expression. In one report, Allis and coworkers (Brownell et al. 1996) described a histone acetyltransferase and discovered that it was GCN5, whose gene was previously identified in yeast using a genetic screen scoring for transcriptional regulators. In a second report, Schreiber and coworkers (Taunton et al. 1996) uncovered that a histone deacetylase resides in a mammalian homolog of yeast RPD3, originally isolated in genetic screens scoring for transcriptional repressors. These were groundbreaking discoveries. Subsequent developments enhanced their impact by showing that the enzymatic activities of Gen5 and $\mathrm{Rpd} 3$ are regulated through their association with other proteins (Sterner and Berger 2000; Kuzmichev and Reinberg 2001). These findings galvanized the field of chromatin research, within the context of transcriptional regulation and gene expression. We now know that many regulators of transcription contain activities that covalently modify the histone tails (Struhl 1998; Sterner and Berger 2000).

Another important finding that intersected histone methylation with heterochromatin formation came about 4 years later. Jenuwein and colleagues (Rea et al. 2000) uncovered that the mammalian homolog of a gene initially isolated in Drosophila as a suppressor of variegation, Suv39H1, and its Schizosaccharomyces pombe homolog, CLR4, encode proteins with intrinsic histone lysine methyltransferase (HKMT) activity. These respective HKMT activities exhibited a strict specificity for lysine- 9 of histone H3, a residue previously identified as being methylated in vivo (DeLange et al. 1973). Lysine residues can potentially be fully methylated generating trimethylated moieties; however, HKMTs can incorporate mono-, di-, or trimethyl groups (Zhang and Reinberg 2001), providing another level of diversity in regulation. The bond formed between the side chain of lysine and the methyl group is not easily reversed (Bannister et al. 2002; Kubicek and Jenuwein 2004). The stability of this lysinemethyl bond is a unique property of this modification. Similar to clusters of $\mathrm{CpG}$ methylation in DNA, histone lysine methylations are now appreciated as stably modified chromatin constituents whose transfer from mother to daughter cells qualifies the epigenetic process. Thus, histone lysine methylations are categorized as "epigenetic marks" (Jenuwein and Allis 2001; Sims et al. 2003). Importantly, numerous studies have provided evidences that the enzymes responsible for the modifications of histones function in a coordinated pattern to control gene expression (Berger 2002; Ng et al. 2002; Sun and Allis 
2002; Krogan et al. 2003; Wood et al. 2003). This ranges from short- to long-term effects, with the latter involving the heritable transferral of stable modifications from mother to daughter cells.

The molecular means by which the transcriptional machinery deals with the repressive nature of unfolded chromatin is one level of complexity being investigated by many laboratories including ours. How higher-order chromatin unfolds to allow access of transcription factors to DNA represents the next level. Our current studies are geared toward the identity and biochemical properties of the proteins required for the formation of higher-order chromatin (heterochromatin) and its unfolding to euchromatin, the template of the transcriptional machinery. In this chapter, we describe our studies on two HKMTs that target sites within the histone tails that function in the establishment of repressive facultative heterochromatin. The sites independently targeted for methylation are lysine-20 of histone $\mathrm{H} 4$ and lysine- 27 of histone H3. We describe our studies toward understanding how these "repressive marks" might be transmitted from mother to daughter cells.

\section{PR-SET7}

A big step toward analyzing how dividing cells can retain tissue identity came about with the isolation of the human protein, PR-Set7, which specifically methylates lysine-20 of histone H4 (Nishioka et al. 2002). PR-Set7 was found to be nucleosomal specific. Our initial biochemical and immunofluorescence experiments using tissue culture cells confirmed that PR-Set7 catalyzed methylation of H4 lysine-20 within nucleosomes (Nishioka et al. 2002). Recent structural studies demonstrated that PR-Set7 is a monomethylase (B. Xiao et al., unpubl.).

We uncovered that methylation of histone H4-lysine20 correlates with the presence of repressive chromatin in vivo (Nishioka et al. 2002). Moreover, other studies uncovered that monomethylation of H4-K20 is present in the inactive female $\mathrm{X}$ chromosome (Kohlmaier et al. 2004). This finding together with our observations led us to conclude that monomethylation of H4-K20 is a repressive mark associated with facultative heterochromatin. Consistently, the "mark" set by PR-Set7 was found to be present in the euchromatic arms of Drosophila polytene chromosomes, but excluded from loci associated with the transcriptionally active form of RNA polymerase II (Fig. 1). Most important to our goals was the discovery that the expression of PR-Set7 was regulated during cell division (Rice et al. 2002). PR-Set7 was found to be expressed early during mitosis in human cells (Fig. 2) and to be bound to mitotic human chromosomes during prometaphase, prior to separation of the chromosomes (Fig. 3). These findings placed PR-Set7 at a time and position appropriate for propagating the methyl mark to newly generated chromatin templates.

From the studies described above, at least two important questions remained unanswered: (1) Although PRSet7 is a monomethylase, does it somehow participate in di- and trimethylation of H4-K20 that occurs in vivo? And (2) what are the in vivo evidences demonstrating that methylation of H4-K20 is a stable mark that can be propagated from mother to daughter cells?

Immunofluorescence studies using highly specific antibodies that distinguish between the three different states of H4-K20 methylation, together with the expression of various SET domain-containing proteins in tissue culture cells, uncovered two novel genes, distinct from PRSET7, that mediate di- and trimethylation of H4-K20 in mammals (Schotta et al. 2004). Interestingly, di- and trimethylation of H4-K20 was dependent on the expression of the Suv3-9H1/2 enzymes, which catalyze trimethylation of H3-K9 (Rea et al. 2000). This finding underscores that the enzymes responsible for the modifications of histone tails function coordinately to control gene expression and chromatin structure, as observed by others (Berger 2002; Ng et al. 2002; Sun and Allis 2002; Krogan et al. 2003; Wood et al. 2003). Di- and trimethylation of H4-K20 was found to be catalyzed by SUV4-20h1/2 in mammals and the "mark" established by these enzymes was found to be primarily pericentromeric (Schotta et al. 2004); i.e., corresponding to constitutive heterochro-
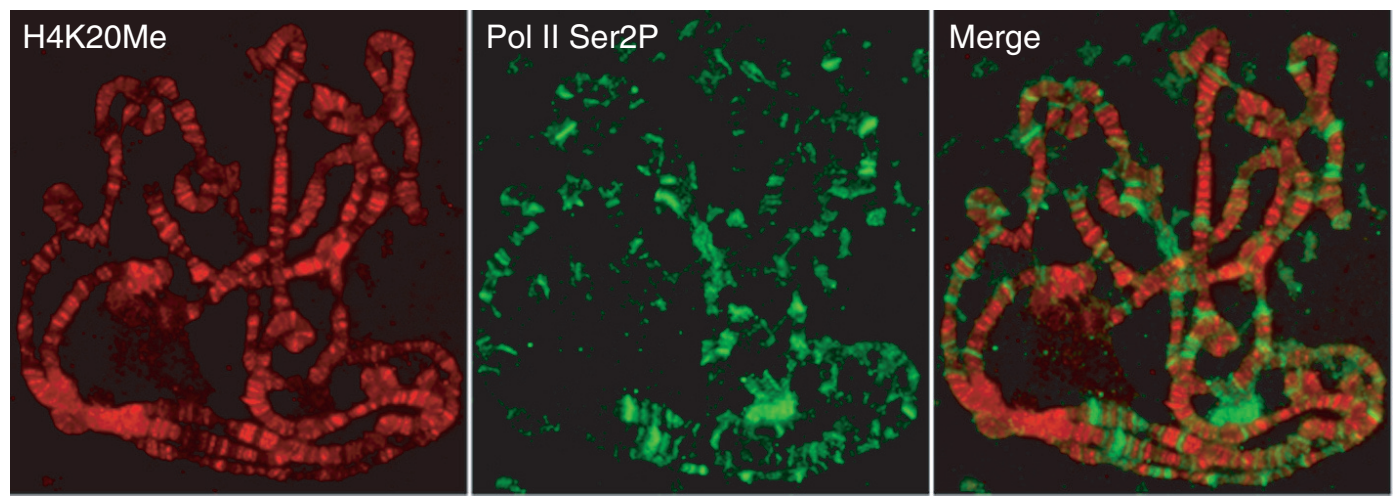

Figure 1. H4 lysine-20 methylation is a mark for repression. Drosophila polytene chromosomes were costained with polyclonal antibodies to H4 methyl-K20 (red) and monoclonal antibodies recognizing the elongating, Ser2-phosphorylated form of RNA polymerase II (green). H4 methyl-K20 and actively transcribing RNA polymerase II are mutually exclusive suggesting that the methyl mark at H4 lysine-20 is repressive. (Adapted from Nishioka et al. 2002.) 


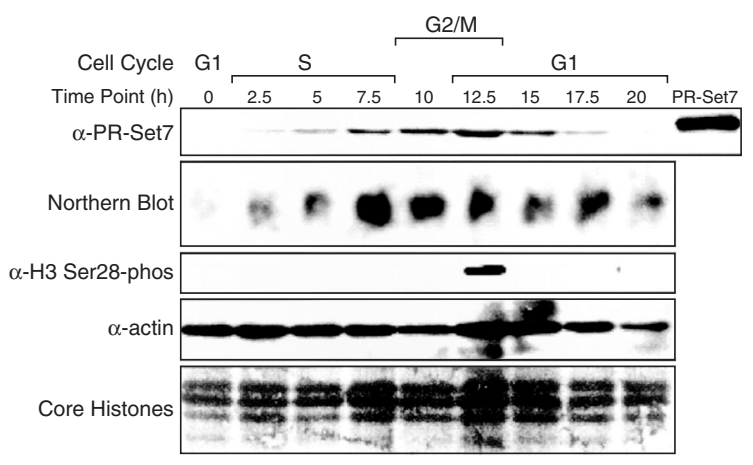

Figure 2. PR-Set7 is up-regulated in mitosis. HeLa cells were synchronized by cell cycle arrest in the G1 phase and released. Cells were collected every $2.5 \mathrm{hr}$. RNA levels were analyzed by northern blot with a probe corresponding to the open reading frame of PR-Set7. Protein levels and H3-Ser28 phosphorylation, which is a mitotic marker, were analyzed by western blot. Actin as well as the Ponceau staining of histones served as loading controls. PR-Set7 protein levels are maximal in the G2/M phase of the cell cycle and overlap with H3-Ser28 phosphorylation, confirming that PR-Set7 is a mitotic HKMT. (Adapted from Rice et al. 2002.)

matin. This is distinct from monomethylation at $\mathrm{H} 4-\mathrm{K} 20$, a mark present within facultative heterochromatin (Nishioka et al. 2002; Kohlmaier et al. 2004). Thus, disparate enzymes catalyze the monomethylation versus the di-and trimethylation of H4-K20 in mammalian cells.

The expression of PR-Set7 during early mitosis and its physical association with mitotic chromosomes in mam-
$\alpha$-PR-Set7
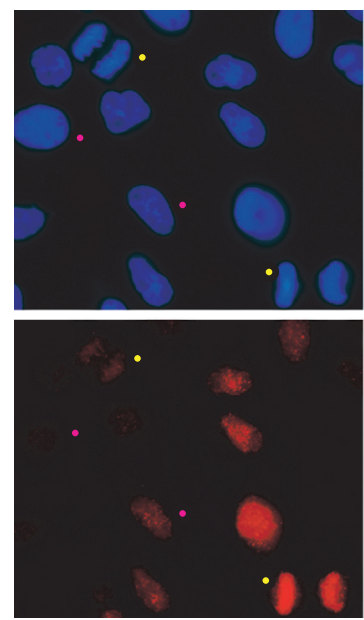
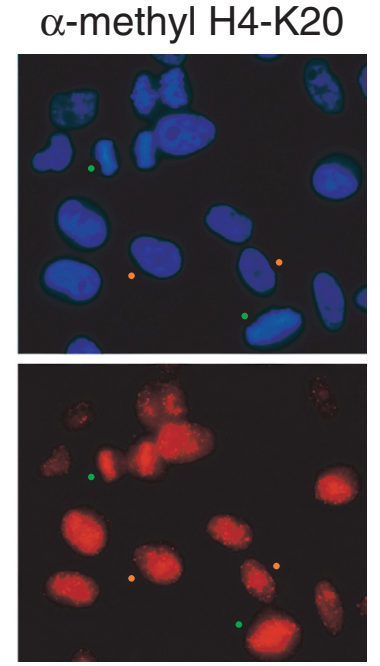

Figure 3. PR-Set7 localizes to mitotic chromosomes. Immunofluorescence staining of PR-Set7 (left, red) and methyl H4-K20 (right, red) in HeLa cells shows that PR-Set7 is up-regulated in the mitotic phase (yellow dots) and localizes to the chromosomes. In interphase cells (pink dots), the levels of PRSet7 are low or not detectable. The staining of methyl H4-K20 (right, red) shows that this modification is also associated with mitotic chromosomes (green dots), but it is still present in interphase cells (orange dots). This might be attributable to the stability of the methyl-lysine mark over several cell generations. The mitotic phases were determined by DAPI staining (blue). (Adapted from Rice et al. 2002.) malian tissue culture cells suggested that monomethyl H4-K20 might be a transferable chromatin mark. Strong evidence for this epigenetic feature comes from studies in Drosophila. By employing P element mobilization, we isolated a null allele in Drosophila PR-SET7 such that the entire protein coding region is missing $\left(P R-S e t 7^{20}\right)$. Interestingly, while PR-Set7 was maternally deposited in the homozygous $P R \operatorname{Ret} 7^{20}$ embryo, it did not persist into the first-instar larval stage (Fig. 4). Yet the monomethyl mark was detectable until late larval stages (data not shown, see below) indicating that once set, this mark is stable over several subsequent cell generations. The absence of PR-Set7 resulted in lethality at the larval to pupal transition (Nishioka et al. 2002; Karachentsev et al. 2005). $P R-S e t 7^{20}$ now allowed us to define the functional role of PR-Set7 and of H4-K20 monomethylation in the organism.

Position effect variegation (PEV) monitors the spread of silent heterochromatin through an inserted euchromatic, active region. The extent of PEV is reflected by a phenotypic change, such as eye color, associated with the levels of expression of the inserted gene. PEV is suppressed in $\operatorname{Pr}-\operatorname{Set}^{20}{ }^{20}$ when insertions into the centromeric and telomeric heterochromatin of the fourth chromosome are analyzed. Thus, PR-Set7 functions, like the enzymes that trimethylate $\mathrm{H} 4-\mathrm{K} 20$ and $\mathrm{H} 3-\mathrm{K} 9$, as a suppressor of variegation $(\mathrm{Su}(\mathrm{var}))$, confirming its role in gene silencing. Surprisingly, and in contrast with results obtained in mammalian tissue culture cells, the levels of all three methyl H4-K20 marks were reduced in $P R-S e t 7^{20}$ mutant larvae (Fig. 5). This may be related to the temporal sequence of the marks attained during early wild-type embryogenesis with monomethyl preceding the di- and trimethyl marks in Drosophila. Of note, there are two enzymes that catalyze di- and trimethylation of H4-K20 in mammals, while only Suv4-20 performs this function in Drosophila (Schotta et al. 2004).

The levels of PR-Set7 cycle and are highest during the late G2 phase through the early M phase. Notably, we found that PR-Set7 is important to the mitotic process. $\operatorname{Pr}-\operatorname{Set}^{20}$ larval imaginal leg and eye discs contained fewer cells than did their wild-type counterparts and these cells had elevated DNA levels (Fig. 6).

These results collectively led us to conclude that (1) monomethylation of histone H4-K20 localizes with transcriptionally inactive, condensed chromatin and (2) PRSet7 expression occurs at the time during mitosis when fresh DNA templates are available to be marked and must be so modified for sustained cell division. PR-Set7 may well be determinant to restoring the repression of cell cycle regulatory genes, a possibility that awaits further investigation. We postulate that binding of PR-Set7 to mitotic chromosomes establishes the basis for propagation of this stable mark through cell divisions. PR-Set7 would recognize monomethylation of histone H4-lysine-20 in the mother chromosomes and transmit this mark to the daughter chromosomes before their separation. This is indeed a very exciting proposition because the modification can be passed down to daughter cells prescribing the silence or expression of genes (in other words, determining the cell's identity). 


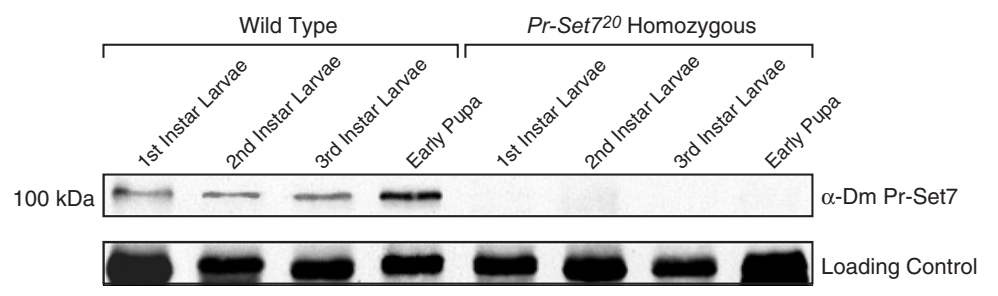

Figure 4. Maternally deposited PR-Set7 does not perdure into late larval stages in PR-Set7 homozygous null flies $\left(P R-S e t 7^{20}\right)$. Different developmental stages of wild-type and $P R$ $\operatorname{Set}^{20}$ flies were analyzed for levels of PRSet7 protein. Although maternal PR-Set7 is deposited into eggs and is present in early embryogenesis (data not shown), it is absent from the first-instar larval stages. In contrast, the $\mathrm{H} 4$ monomethyl mark is detectable, albeit much reduced, even in the third-instar larval stage, as seen in the polytene chromosome staining in Fig. 5. (Adapted from Karachentsev et al. 2005.)

While PR-Set7 may establish heritable cellular identity during mitosis, the histone lysine methyltransferase discussed next, Ezh2, may do so during DNA replication.

\section{EZH2}

Ezh2 is an HKMT that exists in at least three different large protein complexes that share common subunits (Fig. 7A). Remarkably, many of these subunits exhibit altered expression levels during cellular transformation. Particularly noteworthy is that one component is enriched in undifferentiated and transformed cells. The resultant change in the complexes harboring Ezh2 directly alters the histone substrates that are targeted. As discussed below, we postulate that this alteration in histone substrate specificity has profound effects on the pattern of Ezh2targeted gene expression.

As in many cases, the history of Ezh2 is an interesting one. Early studies in Drosophila capitalized on two distinct processes functionally relevant to gene repression. One such phenomenon was the long-term transcriptional silencing of homeotic genes whose regulation was determinant to proper embryonic development (Pirrotta and Rastelli 1994). The Polycomb group (PcG) of proteins was identified as being crucial to this process (Jacobs and van Lohuizen 1999). How these proteins repress tran- scription is a field of active investigation (Lund and van Lohuizen 2004), but it is known that they exist in different multiprotein complexes. The second phenomenon is $\mathrm{PEV}$, whereby the repositioning of an active reporter gene within a heterochromatic region results in its repression. This was insightfully employed as an assay to identify genes that, when mutated or altered in expression, may suppress or enhance PEV. Such candidates were recognized as somehow maintaining the integrity of heterochromatin. The characterization of Ezh2 discussed below demonstrates that it is an HKMT whose activity bridges both phenomena.

Ezh2 was one of the first to be identified as a member of the SET domain family of proteins that includes PRSet7. In most cases the SET domain is associated with lysine-specific methyltransferase activity. Overexpression of Ezh2 was known to enhance PEV (Laible et al. 1997). We set out to examine whether this Ezh2-associated gene repression correlates with its putative HKMT activity.

Our first evidence that the characterization of Ezh2 would prove to be intriguing was that recombinant Ezh2 isolated from bacteria was devoid of HKMT activity (data not shown). A clue that other proteins may be important in eliciting Ezh2 activity was contained in a previous report demonstrating that Ezh2 exists in a complex with other proteins. Only two components of this com-

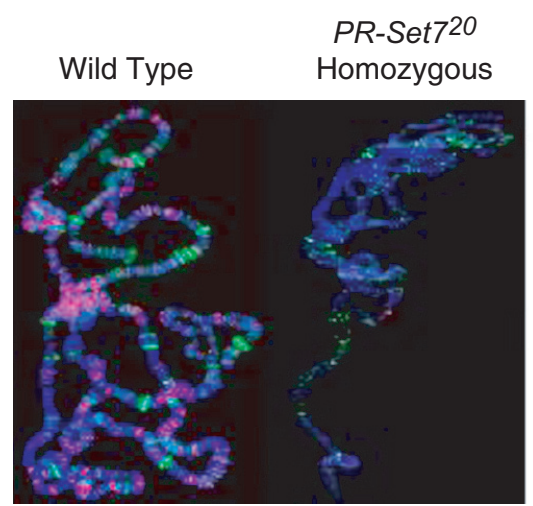

Anti-H4 Monomethyl K20

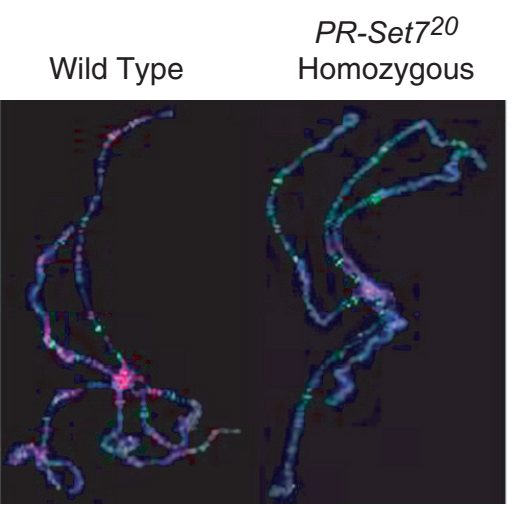

Anti-H4 dimethyl K20

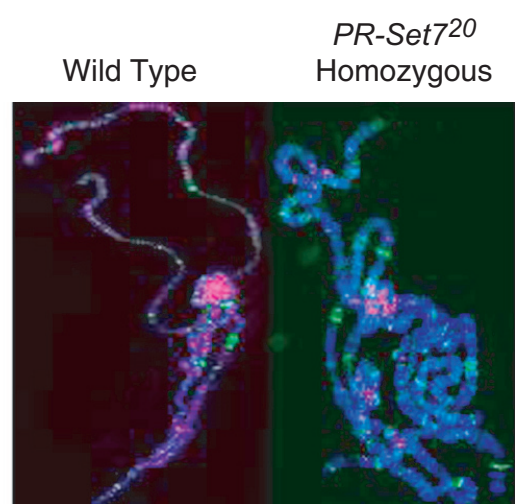

Anti-H4 trimethyl K20

Figure 5. Mono-, di-, and trimethyl levels of H4-K20 are reduced in PR-Set7 homozygous null flies. Immunofluorescence staining of polytene chromosomes from wild-type and $P R-\operatorname{Set}^{20}$ flies show that the mutant flies have very low levels of monomethyl K20 (left). The di- and trimethyl levels (middle and right, respectively) are also reduced. The staining of RNA polymerase II (green) is not altered in the mutants, indicating that the loss of methyl marks from the polytene chromosomes is not a result of chromosome degradation. (Adapted from Karachentsev et al. 2005.) 
A

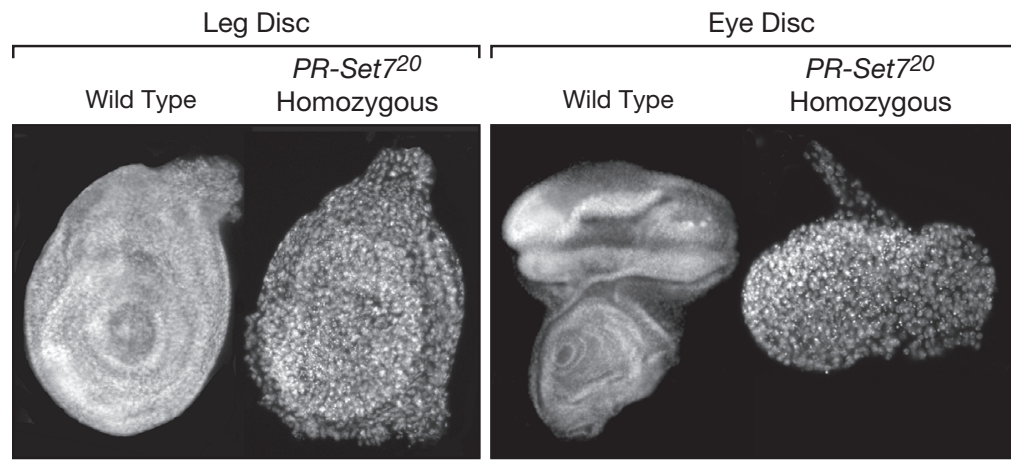

B
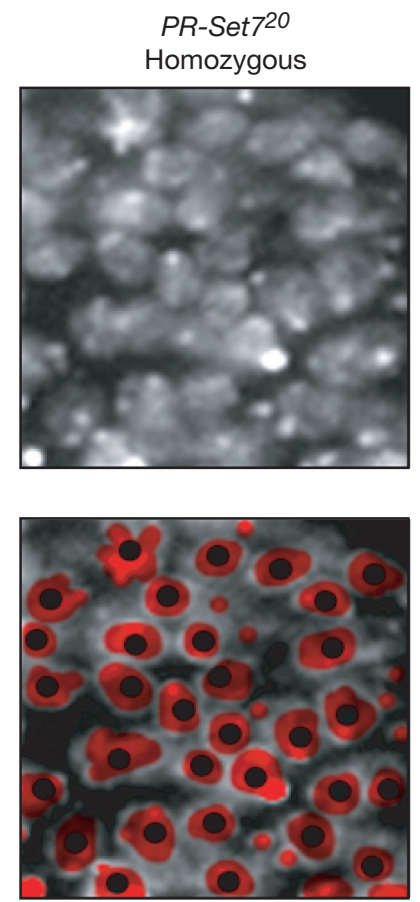

Cell count $=32$

Average DAPI Fluorescence $=100$ units Fluorescence per cell $=3.125$

Fluorescence radio $=3.29$
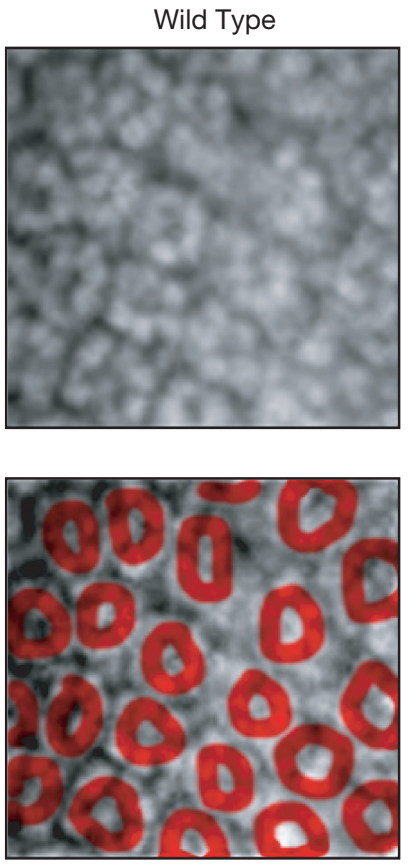

$21 \times 6=126$

Average DAPI Fluorescence $=120$ units Fluorescence per cell $=0.95$ from Karachentsev et al. 2005.)

plex were identified at that time, Ezh2 and the PcG protein ESC (Drosophila homolog of mammalian Eed) (Ng et al. 2000). Nonetheless, given that Ezh2 did not function in isolation, this suggested to us that its association with other proteins might regulate its activity. As described below, this was indeed the case. Not only did associated proteins elicit Ezh2 activity but several such complexes were identified. While these complexes shared many subunits, such as Ezh2, they differed in others and this correlated with the differential substrate specificity exhibited by the enzyme (see Fig. 7A).

Using standard chromatographic techniques, we initially detected two complexes that contained Ezh2 in mammalian tissue culture cells. Purification of one of these complexes followed by mass spectrometry in conjunction with immunoblotting revealed that, in addition to Ezh2 and ESC (mammalian Eed), the complex contained another PcG protein, JJAZ1 (the human homolog of Drosophila $\mathrm{Su}(\mathrm{z}) 12)$, as well as the histone-binding proteins RbAp46 and RbAp48 (Fig. 7) (Kuzmichev et al. 2002). We designated this complex PRC2, as another complex containing a completely different set of PcG proteins had been previously designated Polycomb Repressive Complex 1 or PRC1 (Shao et al. 1999). The PRC2 complex was also isolated from cells that were stably transformed with ESC containing a FLAG tag (Kuzmichev et al. 2002).

Analysis of the second Ezh2-containing complex revealed it to be similar in polypeptide composition to PRC2; however, the Eed species contained in this complex differed to that present in PRC2 (Fig. 7). We referred to this complex as PRC3.

Further investigation using tissue culture cells revealed that Eed protein is actually present in four different isoforms (Eed1-4) with the largest species being Eed1 (Fig. 7B; and see below). These isoforms appear to arise from 


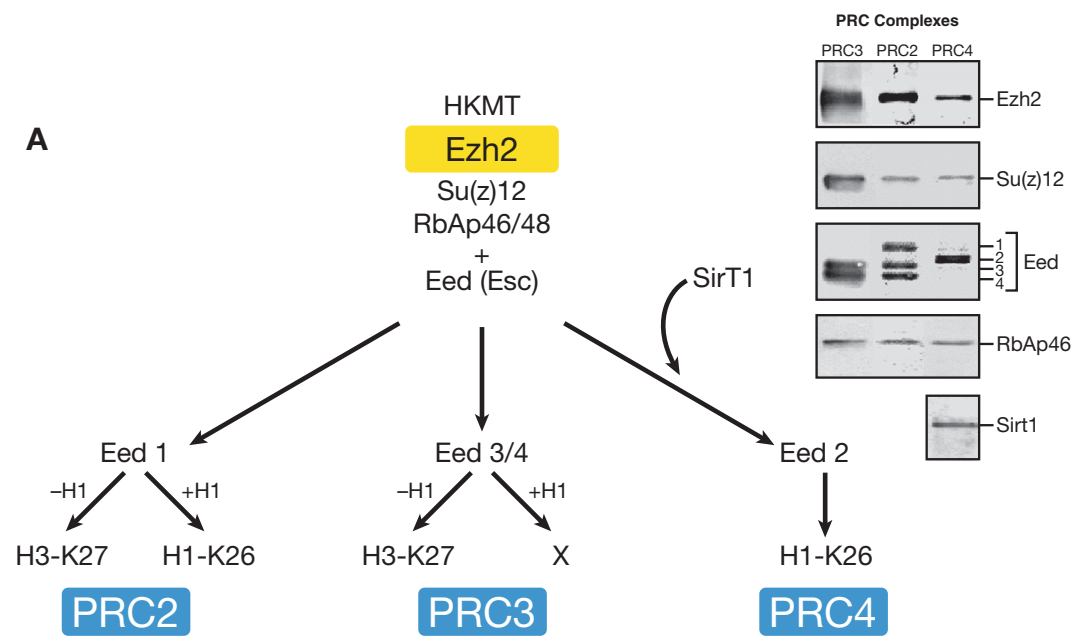

B

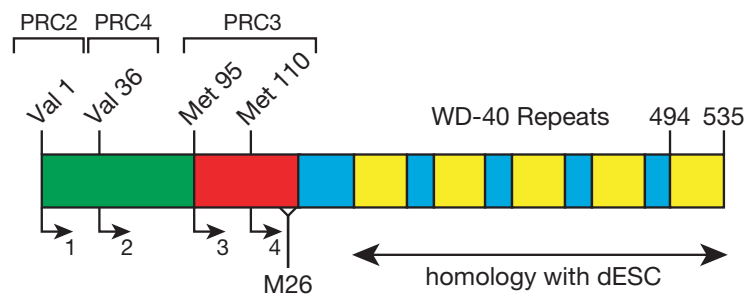

Figure 7. PRC complexes and Eed protein. (A) Left: Summary of the different PRC complexes showing their composition and substrate specificities. Right: Western blot for the PRC components with partially purified PRC2/3/4. (B) Schematic representation of the Eed protein. (Adapted from Kuzmichev et al. 2004.)

the use of different translational start sites present in Eed mRNA (Fig. 7B) (Denisenko et al. 1998; Kuzmichev et al. 2004). PRC2 was enriched in Eed1 and PRC3 contained exclusively Eed3 and Eed4 (Fig. 7A). Neither complex contained Eed2. Were these differences in the Eed isoform determinant to the function/activity of the PRC2/3 complexes?

In contrast to Ezh2 in isolation, PRC2 and PRC3 now exhibited HKMT activity and this was dependent upon the SET domain of Ezh2 (Kuzmichev et al. 2002, 2004). Given octamers in isolation, PRC2 and PRC3 both targeted histone H3-lysine-27 (H3-K27) for methylation (Kuzmichev et al. 2002, 2004). However, when histone $\mathrm{H} 3$ was present in the form of oligonucleosomes containing histone $\mathrm{H} 1$, presumably the natural substrate in vivo, differences in PRC2 and PRC3 activity were detected. PRC2 additionally targeted lysine-26 of histone H1 (H1K26) for methylation, but the presence of $\mathrm{H} 1$ repressed PRC3 activity completely (Fig. 7A). As histone H1 had not been documented as a substrate for lysine methylation, the first issue to address was whether or not H1-K26 is methylated in vivo. Indeed, by generating antibodies specific for me-H1-K26, we observed immunoreactivity against native, but not recombinant, histone H1. Importantly, the stretches of amino acid sequence immediately surrounding H1-K26 and H3-K27 are remarkably similar (Fig. 8) and likely contribute to their targeting by Ezh2. We hypothesize that the disparity in Eed makeup of PRC2 and PRC3 is determinant to the differences in their substrate specificity. Indeed, as described below, we isolated a novel PRC that exhibited yet another difference in substrate specificity. This complex contained the elusive Eed2 isoform and the conditions that spurred its formation were quite notable (Fig. 7A; and see below).

Given the biological relevance of methylated histone H1, instead of focusing on Ezh2-containing complexes, we next sought activities other than PRC2 that may methylate lysine residues of histone H1 (H1-HKMT) from crude HeLa cell extract. We found at least two such activities (Kuzmichev et al. 2005). One of them was a mixture of PRC2 and PRC3. Interestingly, another species displayed the highest level of activity and had a larger molecular mass, and yet its composition was similar to PRC2 and PCR3 as it included Ezh2, Su(z)12, Eed, and RbAp46/48 polypeptides. However, we noticed a distinct difference between this complex and PRC2/3 at this point in our analyses. This larger complex specifically contained the elusive Eed2 isoform (Figs. 7A and 9). Thus, our search for additional H1-HKMT activity

\begin{tabular}{|c|c|}
\hline rtkgtarkstga & Human H3-K9 \\
\hline latkaarksapa & Human H3-K27 \\
\hline rkkarksaga & Human $\mathrm{H} 1 \mathrm{~b}(\mathrm{H} 1.4)$ \\
\hline kkaakkag & Human H1d (H1.2) \\
\hline skkstdhpkysd & Human $\mathrm{H} 1^{\circ}$ \\
\hline
\end{tabular}

Figure 8. Alignment of sequence surrounding H3-K9, H3-K27, and H1-K26. Alignment of the human sequence surrounding $\mathrm{H} 3-\mathrm{K} 9, \mathrm{H} 3-\mathrm{K} 27$, and H1-K26 from different $\mathrm{H} 1$ isoforms and the corresponding sequence from $\mathrm{H} 1^{\circ}$ is shown. The two existing nomenclatures for $\mathrm{H} 1$ isoforms are indicated. 

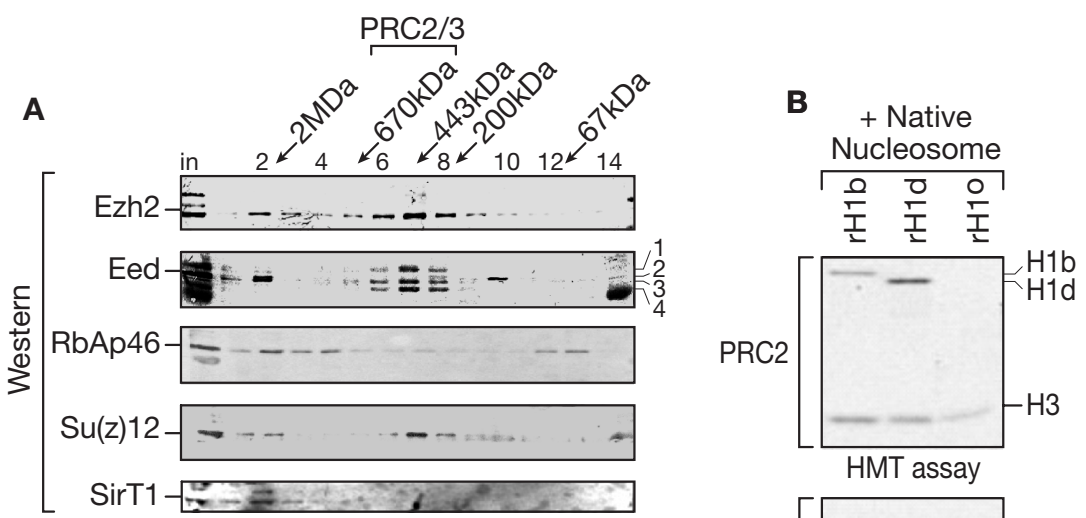

Figure 9. PRC4 identification and substrate specificity. (A) Gel filtration analysis of the PRC4 complex. Fraction numbers and corresponding molecular weight standards are indicated at the top. Top: Western blot of column fractions using indicated antibodies. Bottom: HKMT assays of column fractions performed with substrates indicated on the left. (B) Comparison of PRC2 and PRC4 methylation of $\mathrm{H} 1$ isoforms. (Adapted from Kuzmichev et al. 2005.)
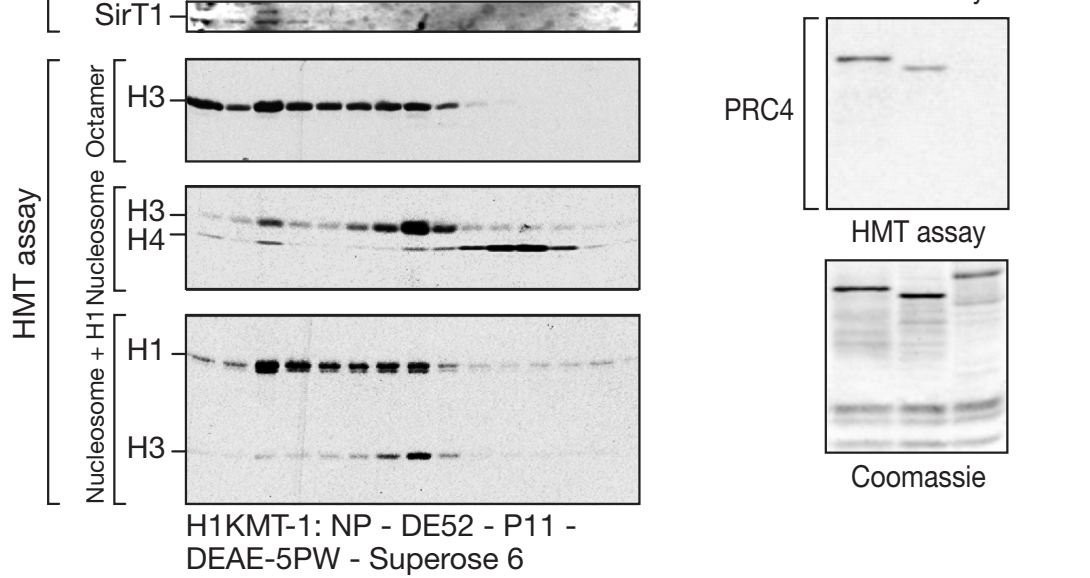

other than that associated with PRC2 revealed a novel PRC as judged by its composition. We designated this complex PRC4.

The substrate specificity of PRC4 was most similar to that of PRC2. In the absence of H1, PRC4 methylated histone H3-K27 when present in oligonucleosomes. However, in contrast to PRC2, PRC4-mediated methylation of H3 was greatly reduced when H1-containing oligonucleosomes were the substrates (Fig. 9A). Similar to PRC2, PRC4 now preferentially methylated H1-K26. Further analyses did reveal a distinction in PRC2 and PRC4 substrate preferences. While PRC2 preferentially methylated the histone H1d isoform (human H1.2), PRC4 preferentially targeted H1b (human H1.4) (Fig. 9B). None of the complexes methylated $\mathrm{H}^{\circ}{ }^{\circ}$, which lacks lysine-26 (Fig. 8). Thus PRC2, PRC3, and PRC4 differed in the specific Eed isoform(s) they contained and this correlated with their differential substrate preferences.

Further examination of PRC4 revealed another significant difference in its composition and associated activity relative to PRC2 and PRC3. We thought it possible that SirT1 might be associated with one or more of the PRCs, based on the following findings. Our studies had identified SirT1 as a NAD ${ }^{+}$-dependent histone deacetylase. It exhibited specificity for $\mathrm{H} 1-\mathrm{K} 26$, the same residue that is methylated by PRC4 and PRC2 (Vaquero et al. 2004). We noted that methylation of $\mathrm{H} 3-\mathrm{K} 9$ is known to be facilitated by its prior deacetylation through HDAC1 in Drosophila (Czermin et al. 2001) and by deacetylation through the $\mathrm{NAD}^{+}$-dependent deacetylase spSir2 in $S$. pombe (Shankaranarayana et al. 2003). Thus, SirT1 may function analogously to HDAC1 or spSir2, but with respect to H1-K26. Moreover, a connection between SirT1 and Ezh2 was revealed by their independent participation in PEV (Laible et al. 1997; Rosenberg and Parkhurst 2002). Following this hunch, we found that SirT1 was indeed associated, specifically with PRC4 (Figs. 9A and 10A), in a manner dependent on SirT1 enzymatic activity (Fig. 10A). Moreover this association was specific because the related SirT2 failed to interact with the PRC4 complex (Fig. 10). In fact, SirT1 interacts directly with $\mathrm{Su}(\mathrm{z}) 12$ (Fig. 11). As $\mathrm{Su}(\mathrm{z}) 12$ is a common subunit of PRC2-4, the fact that SirT1 associates solely with PRC4 is intriguing. Perhaps the specific Eed isoforms present in the PRCs determine their HKMT substrate specificity and also the availability of the $\operatorname{Su}(\mathrm{z}) 12$ epitope necessary for SirT1 interaction. This remains to be examined. Determining if SirT1 was relevant to PRC-regulated gene expression in vivo was of high priority.

We initially identified PRC-regulated genes through a combination of approaches. We first sought genes whose expression may change upon down-regulation of one of the PRC common subunits, $\mathrm{Su}(\mathrm{z}) 12$. RNA isolated from colon cancer cells that were either untreated or treated with siRNA against $\mathrm{Su}(\mathrm{z}) 12$ was scored using DNA arrays containing $\mathrm{CpG}$ islands (Kirmizis et al. 2004). The latter are enriched for promoter-containing DNA. A group of responsive genes was identified. We then tested for the presence of PRC components at the promoters of these genes in vivo, in wild-type cells. Chromatin immunoprecipitation (ChIP) experiments identified that several of the genes whose expression had responded to 
A
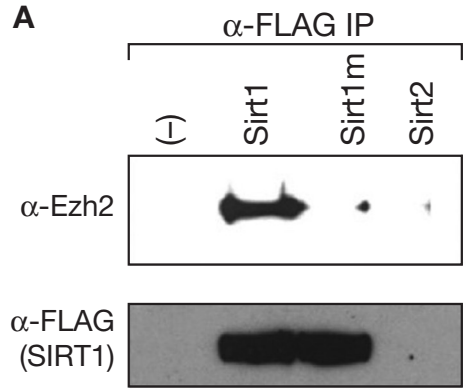

$\alpha-\operatorname{Sirt1}$

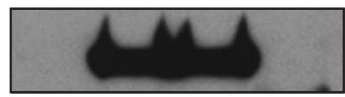

$\alpha-F L A G$

(SIRT2)

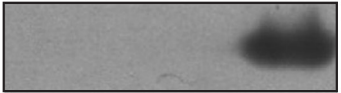

B

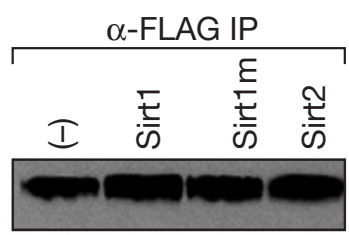

$\alpha-F L A G$

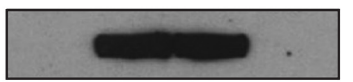

$\alpha-\operatorname{SIRT1}$

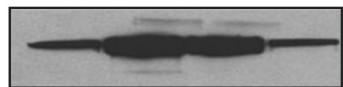

$\alpha$-Eed

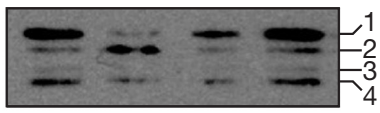

$\alpha-F L A G$

(SIRT2)
Figure 10. SirT1 interacts with the PRC4 complex in mammalian cells. (A) AntiFLAG immunoprecipitation was performed with extracts from 293 cells transfected with expression vectors encoding untagged Ezh2 and FLAG-tagged SirT proteins (wild-type SirT1 ["SirT1" lane], active site mutant SirT1 ["SirT1m" lane], or wild-type SirT2 protein ["SirT2" lane]). The immunoprecipitates were analyzed by western blot using the indicated antibodies. ( $B$ ) Inputs for immunoprecipitation were analyzed by western blot using antibodies as indicated on the left. (Adapted from Kuzmichev et al. 2005.)
$\mathrm{Su}(\mathrm{z}) 12$ deprivation contained $\mathrm{Su}(\mathrm{z}) 12$, Ezh2, and Eed at their promoters in the wild-type case, in vivo. We later found that SirT1 was present at these same PRC-regulated genes (Fig. 11B). Thus, SirT1 is an in vivo constituent of a PRC and our biochemical studies revealed this to be PRC4.

Given the differential substrate specificity exhibited by the distinct PRCs, conditions in the cell that may promote formation of a particular complex would be expected to have marked consequences to the histones that are modified and, thus, to chromatin structure and gene expression. At this stage in our investigations a new report provided an important clue to such conditions, conditions that we found to favor PRC4 formation.

Ezh2 was found to be expressed at increasingly elevated levels during the progression of prostate cancer (Varambally et al. 2002) and the same was true in breast cancer (Kleer et al. 2003). In the context of our biochem-
A
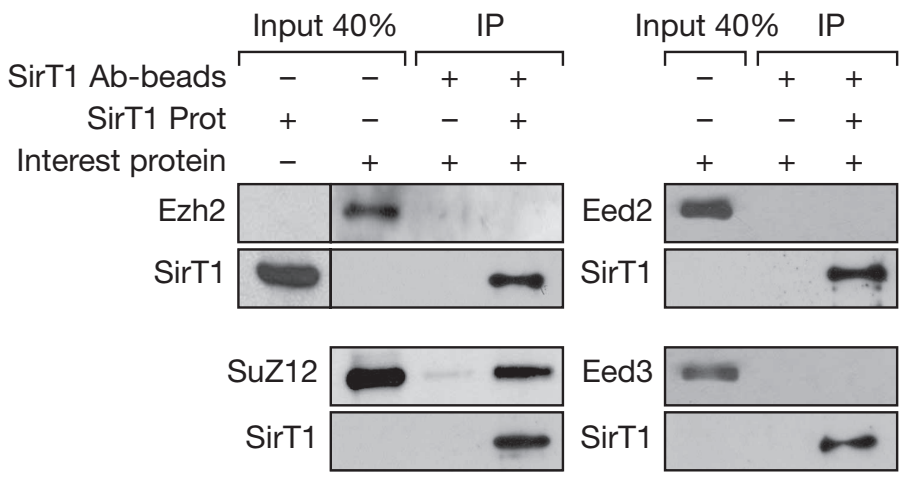

B
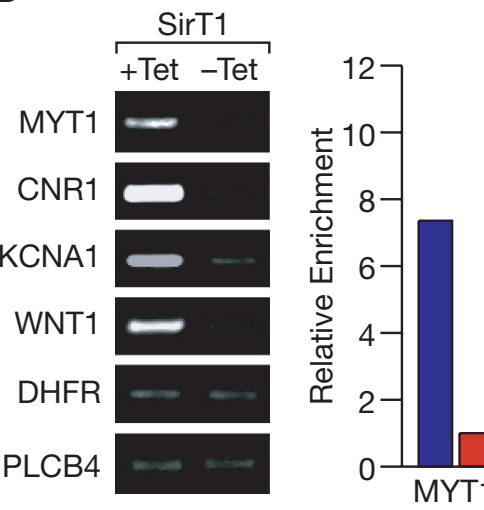

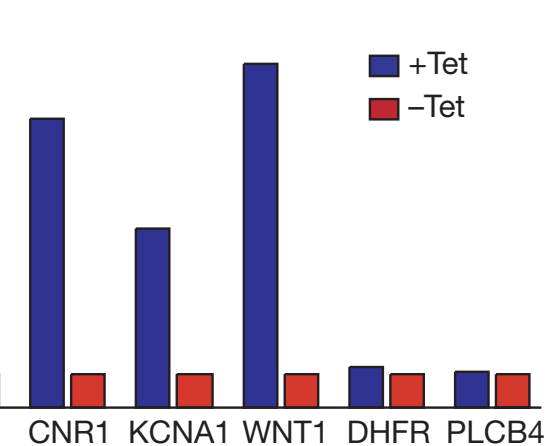

Name of gene promoter
Figure 11. SirT1 interacts with $\mathrm{Su}(\mathrm{z}) 12$ and is present on PRC target promoters. (A) Recombinant Ezh2, Su(z)12, Eed (30-535), or Eed (95-535) derived from Sf9 cells infected with recombinant baculoviruses or from Escherichia coli (Eed proteins) were incubated separately with or without recombinant SirT1 protein and immunoprecipitated using SirT1-specific antibody (2G1; see Vaquero et al. 2004) coupled to beads. Inputs and elutions were analyzed by western blot using antibodies as indicated on the left. (B) Chromatin immunoprecipitation experiments using antibodies to Gal4 were performed in 293 f cells expressing Gal4-SirT1 under the control of tetracycline in its presence $(+$ Tet) or its absence $(-\mathrm{Tet})$. The precipitated chromatin was analyzed with PCR using primers specific to the promoters targeted by PRC2/3 (MYT1, CNR1, KCNA1, and WNT1) and to the negative control promoters (DHFR and PLCB4) as indicated. The relative enrichment of the signal in the absence or in the presence of tetracycline (which causes the induction of Gal4-SirT1) is shown. (Adapted from Kuzmichev et al. 2005.) 


\section{INHERITANCE OF REPRESSIVE METHYL-LYSINE MARKS IN HISTONES}

ical analyses of Ezh2, such overexpression was intriguing. As Ezh2-associated HKMT activity requires its association with the other PRC components, Ezh2 would not be expected to be functional were it to be solely overexpressed. To approach this quandary, we first examined the levels of Ezh2, SirT1, and Eed isoforms during differentiation of mouse embryonic stem (ES) cells in vitro as cancer cells exhibit at least partial dedifferentiation. Previous studies had shown that Ezh2 and Eed levels overall decline during ES cell differentiation (Silva et al. 2003). We further noted that the levels of SirT1 also declined (Fig. 12A). We could now distinguish the four Eed isoforms, all of which were present in undifferentiated cells. Remarkably, Eed1-4 did not decline in unison. The PRC4-specific Eed2 isoform was down-regulated immediately upon induction to differentiate (Fig. 12A). Over time, the only isoform predominately remaining was Eed3. This change in pattern of the Eed isoform levels upon ES cell differentiation was consistent with the profile of Eed expression in normal mouse tissue; the levels of Eed2 are undetectable and Eed3 is predominant.

The state of Ezh2 activity upon its elevation in cancer cells became less perplexing when we observed elevated levels not only of Ezh2, but also of other PRC components: $\operatorname{SirT1}, \operatorname{Su}(\mathrm{z}) 12$, and all four Eed isoforms were elevated in human cancer specimens relative to normal tissue (Fig. 12B). These conditions would favor formation of any of the PRC2-4 candidates, including the SirT1/Eed2-specific PRC4. Similar to differentiated mouse ES cells and normal mouse cells, Eed2 was the only Eed isoform that was undetectable in normal human cells derived from the colon (Fig. 12B). Normal cells appear to favor PRC2 and PRC3 and to be deficient in PRC4. This survey of ES cells as a function of differentiation and of human cells as a function of cellular transformation strongly suggested that there were indeed cellular conditions that discriminate among the PRCs. This was evident in the differential expression profiles of the Eed isoforms that distinguished PRC2-4.

We next investigated the affects on PRC integrity when Ezh2 or SirT1 is overexpressed, this time in tissue culture cells. Biochemical analyses revealed that overexpression of Ezh2 drove PRC4 formation as evidenced by the accumulation of a large complex containing the PRC4-specific components, SirT1 and Eed2 (Fig. 13). Remarkably, overexpression of SirT1 resulted in an altered pattern of Eed isoform expression in the cells with Eed2 now being prominent, thus suggesting that SirT1 overexpression may also lead to PRC4 formation (Fig. 10B). These findings underscore the fact that overexpression of the PRC components can have a direct impact on the composition of the PRCs and can promote formation of the distinctive PRC4. With this basis, we next investigated the levels of PRC components and gene expression profiles during
Figure 12. Expression of PRC components is modulated as a function of differentiation and cellular transformation. $(A)$ Western blot analysis of nuclear extracts from PGK12.1 ES cells. Days of differentiation are indicated above each lane. The western blot was probed with antibodies against SirT1, Ezh2, and Eed as well as control antibody directed against histone H3. (B) Western blot analysis of PRC components using HeLa cell nuclear extracts or whole tissue extracts prepared from normal $(\mathrm{N})$ and tumor $(\mathrm{T})$ tissues obtained from a breast cancer patient and a colon cancer patient. Tissue samples were obtained from the Cooperative Human Tissue Network (CHTN). The blots were probed with antibodies to $\operatorname{Su}(\mathrm{z}) 12$, SirT1, Eed, and actin, which served as a loading control. A long exposure of the same panel containing the normal colon extract probed with Eed antibody is also shown. (Adapted from Kuzmichev et al. 2005.)
A

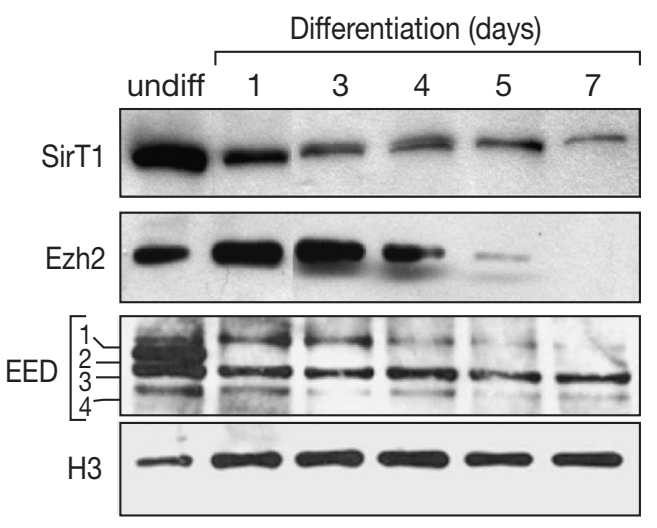

B
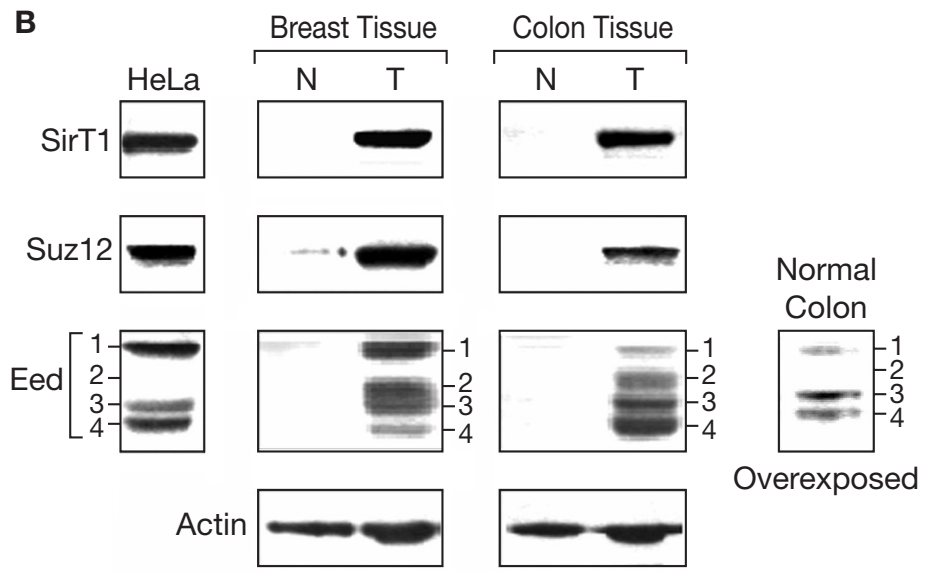
A

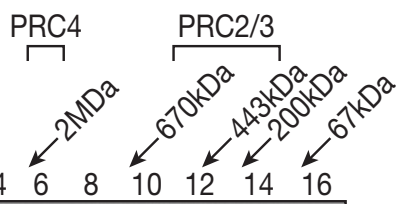

$\alpha-F L A G$
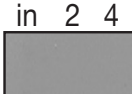

Ezh2
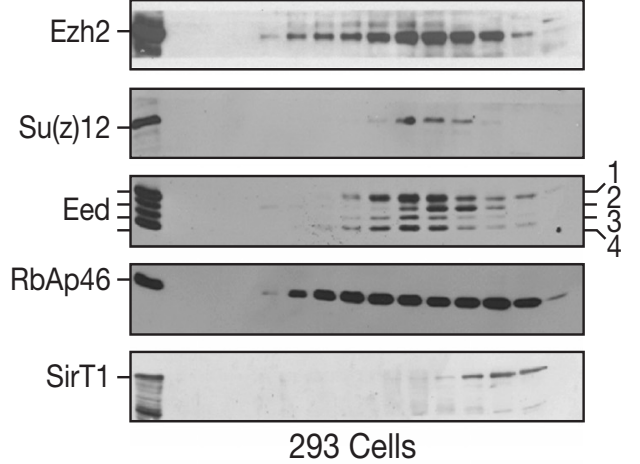

B
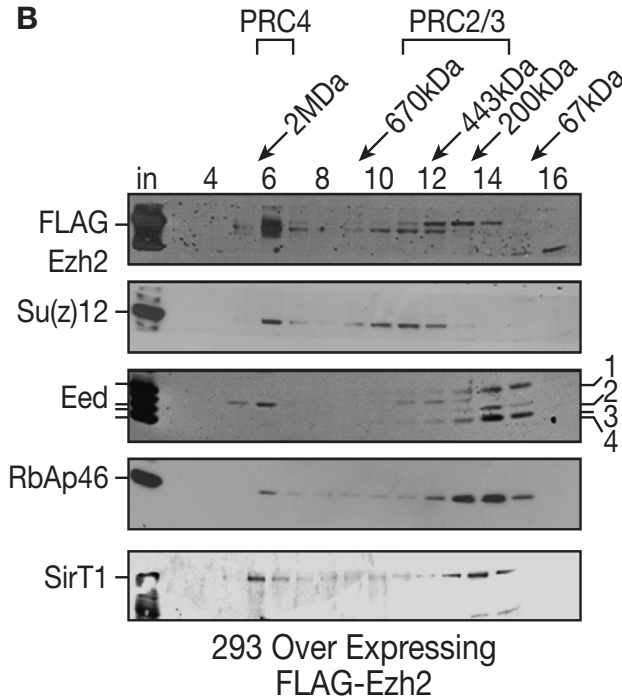

Figure 13. PRC complexes in $293 \mathrm{f}$ cells overexpressing Ezh2. Gel filtration of nuclear extracts derived from $293 \mathrm{f}(A)$ and 293FLAG-Ezh2 $(B)$ cell lines on Sephacryl-400 columns. Fraction numbers and molecular weight standards are indicated on top; "in" corresponds to column input. Western blots were probed with antibodies as indicated on the left. The amount of protein analyzed in $A$ was approximately twice that analyzed in $B$. (Adapted from Kuzmichev et al. 2005.)

discrete stages of carcinogenesis using a well-established mouse model for prostate cancer.

A unique mouse model for prostate cancer was generated based on haplo-insufficiency in two genes that are candidate targets for prostate cancer in humans. Pten is a ubiquitously expressed tumor suppressor gene and Nkx3.1 is a prostate-specific homeobox gene. Mice heterozygotic for these genes $\left(\mathrm{Pten}^{+/} ; \mathrm{Nkx} 3.1^{+/-}\right)$constitute an ideal system for studies covering the range of prostate cancer progression (Abate-Shen and Shen 2002) - an investigation not currently feasible in the case of humans. These mice develop prostatic intraepithelial neoplasia
(PIN) lesions by 6 months of age and adenocarcinoma by 12 months. Following androgen deprivation by castration, these mice develop metastases to the lung and lymph nodes (Fig. 14A) (Abate-Shen et al. 2003). We examined the levels of PRC2, PRC3, and PRC4 components as a function of prostate cancer progression using immunohistochemical analyses. Low levels of Ezh2 and SirT1 were evident in normal prostate. PIN lesions exhibited a moderate elevation and further elevation in Ezh2 and SirT1 levels were evident in cancerous tissue (Fig. 14B). This recapitulated and expanded the previous findings with human specimens. The Ezh2, Su(z)12, and Eed expression levels were further investigated using microarray gene expression profiling. In this case, RNA was isolated after laser-capture microdissection of prostatic lesions through different stages of cancer. These PRC components were all elevated relative to normal tissue (Fig. 14, C and D).

The validity of this mouse model was further buttressed. As discussed above, several PRC-regulated genes had been identified. Some of these genes were down-regulated and others were up-regulated as a consequence of depriving human colon cancer cells of the common PRC component, $\mathrm{Su}(\mathrm{z}) 12$. We now found that these same PRC-regulated genes exhibited a steady, inverse change in expression profiles with cancer progression in the mouse model, relative to normal cells (Fig. 14D).

The elevated levels of PRC components in human cancer cells and during prostate cancer progression in the mouse model has not been shown to be causal to carcinogenesis. This can, however, be tested in the mouse model. For example, the mouse model can be engineered to express the Eed isoforms excluding the PRC4-specific Eed2 and then surveyed for repercussions on prostate cancer progression.

The Ezh2-associated PRCs have proven to be fascinating in that their constitution is a dynamic one reflecting the expression levels of the disparate isoforms of the common Eed subunit. By exchanging one isoform for another, the histone substrate specificity of Ezh2 is alternately regulated in the cell. Given the disparate histone substrate specificities exhibited by PRC2-4, conditions that promote the formation of a particular PRC were suspected to impact on gene expression. Such an outcome has now been substantiated as cellular transformation favors the constitution of PRC4. Consistent with this, PRCtargeted gene expression is demonstrably altered between normal and cancer cells.

\section{ACKNOWLEDGMENTS}

We thank Dr. A. Otte for providing anti-Eed antibodies (M26) and Dr. Lynne Vales for valuable comments on the manuscript. We also thank Xiaohui Sun for immunohistochemistry and Jayshree Rao and Yong Lin for assistance with microarray analyses. We thank Dr. Michael Shen for advice and Dr. John Lis for providing Figure 1. This work was supported by NIH grants to D.R., C.A.-S., and P.F. D.R. is an Investigator of the Howard Hughes Medical Institute. 
A

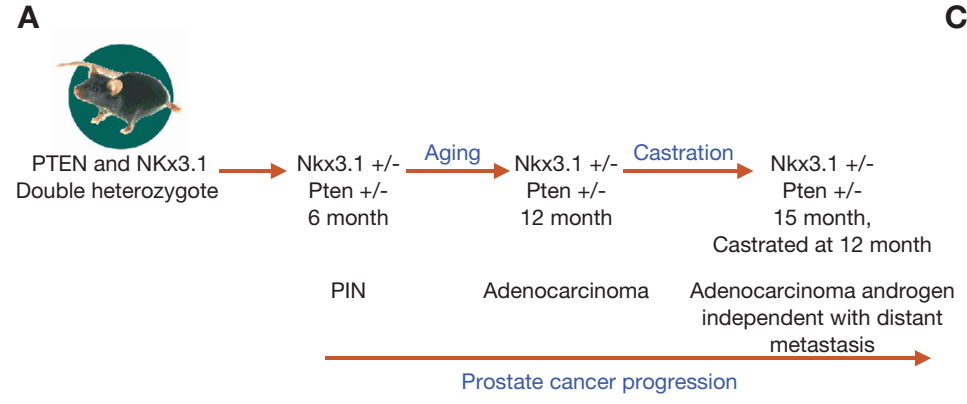

C

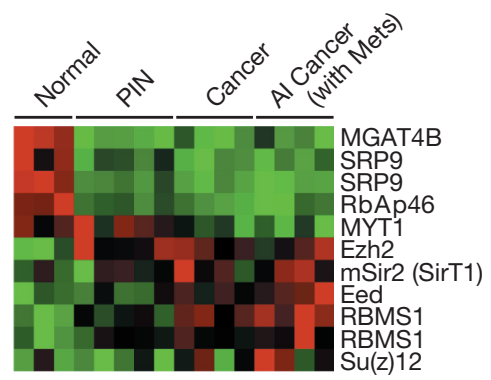

Low
B
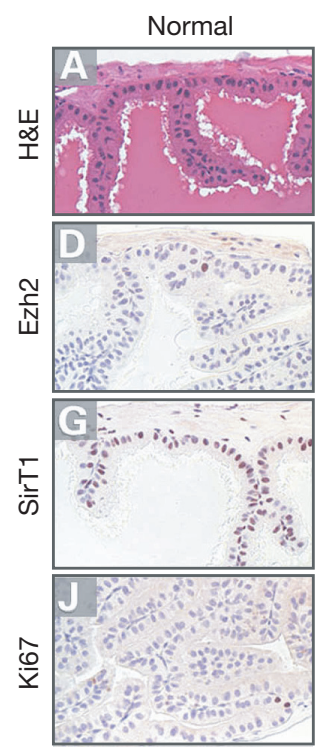

PIN
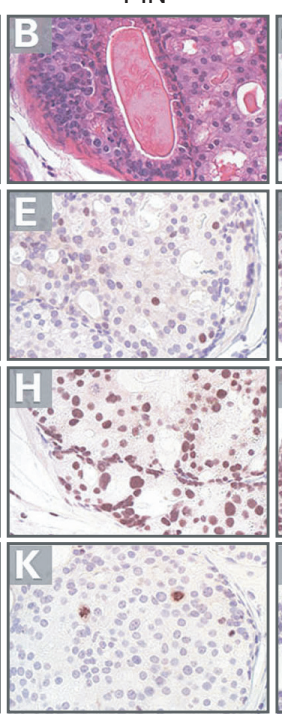

Cancer
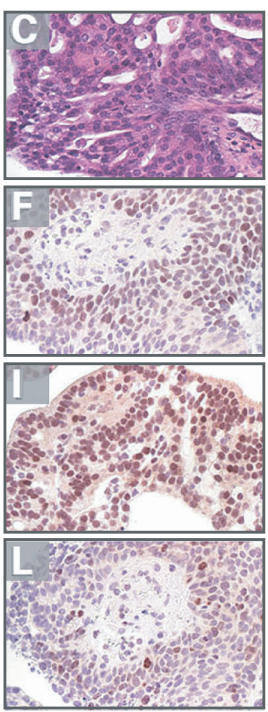

D
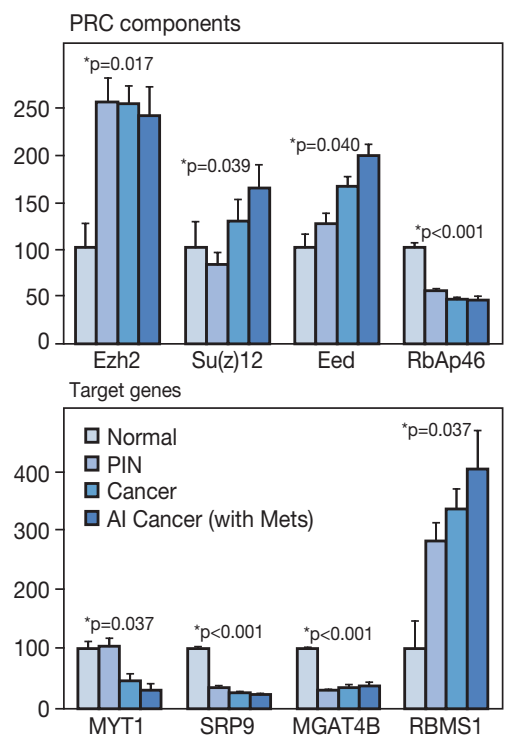

Figure 14. PRC4 components in a mouse model of prostate cancer. $(A)$ Mouse model of prostate cancer. Double heterozygote mice $\left(N k \times 3.1^{+/} ;\right.$Pten $\left.^{+-}\right)$develop prostate intraepithelial neoplasia (PIN) at 6 months and cancer at 12 months. Tumors from mice castrated at 12 months become androgen independent and develop metastases to the lung and lymph nodes. $(B)$ Immunohistochemical detection of SirT1 and Ezh2 in PIN and cancer lesions. Sections from anterior prostates of wild-type and $N k x 3.1^{+/} ; P_{t e n}^{+/-}$mice were processed for hematoxylin-eosin (H\&E) staining $(A-C)$, or immunostained using Ezh2 $(D-F)$, SirT1 $(G-I)$, or Ki67 $(J-L)$ antisera. $(A, D, G, J)$ Sections from a wild-type $N k \times 3.1^{+/+} ;$Pten $^{+/+}$mouse at 9 months of age. $(B, E, H, K)$ Sections from a $N k x 3.1^{+/} ;$Pten $^{+/}$mouse at 12 months. $(C, F, I, L)$ Sections from a Nkx3.1 ${ }^{+/}$; Pten $^{+/}$mouse at 15 months of age. Note that Ezh2 immunostaining is infrequent in normal tissue, but is more common in PIN and carcinoma, while SirT1 is broadly expressed in normal epithelium and stroma, but is up-regulated in epithelial cells in PIN and carcinoma. (C,D) Expression profiling of PRC components and target genes from normal to cancer lesions of prostate from compound mutant mice described in $A$ and performed using RNA obtained by laser-capture microdissection. $(C)$ Tree representation. $(D)$ Quantitative representation of microarray results. (Adapted from Kuzmichev et al. 2005.)

\section{REFERENCES}

Abate-Shen C. and Shen M.M. 2002. Mouse models of prostate carcinogenesis. Trends Genet. 18: S1.

Abate-Shen C., Banach-Petrosky W.A., Sun X., Economides K.D., Desai N., Gregg J.P., Borowsky A.D., Cardiff R.D., and Shen M.M. 2003. Nkx3.1; Pten mutant mice develop invasive prostate adenocarcinoma and lymph node metastases. Cancer Res. 63: 3886

Bannister A.J., Schneider R., and Kouzarides T. 2002. Histone methylation: Dynamic or static? Cell 109: 801 .

Berger S.L. 2002. Histone modifications in transcriptional regulation. Curr. Opin. Genet. Dev. 12: 142.

Brownell J.E., Zhou J., Ranalli T., Kobayashi R., Edmondson D.G., Roth S.Y., and Allis C.D. 1996. Tetrahymena histone acetyltransferase A: A homolog to yeast Gcn5p linking histone acetylation to gene activation. Cell 84: 843 .

Czermin B., Schotta G., Hulsmann B.B., Brehm A., Becker P.B., Reuter G., and Imhof A. 2001. Physical and functional asso- ciation of SU(VAR)3-9 and HDAC1 in Drosophila. EMBO Rep. 2: 915.

DeLange R.J., Hooper J.A., and Smith E.L. 1973. Histone 3. 3. Sequence studies on the cyanogen bromide peptides; complete amino acid sequence of calf thymus histone 3. J. Biol. Chem. 248: 3261.

Denisenko O., Shnyreva M., Suzuki H., and Bomsztyk K. 1998. Point mutations in the WD40 domain of Eed block its interaction with Ezh2. Mol. Cell. Biol. 18: 5634.

Jacobs J.J. and van Lohuizen M. 1999. Cellular memory of transcriptional states by Polycomb-group proteins. Semin. Cell Dev. Biol. 10: 227.

Jenuwein T. and Allis C.D. 2001. Translating the histone code. Science 293: 1074.

Karachentsev D., Sarma K., Reinberg D., and Steward R. 2005. PR-Set7-dependent methylation of histone H4 Lys 20 functions in repression of gene expression and is essential for mitosis. Genes Dev. 19: 431.

Kirmizis A., Bartley S.M., Kuzmichev A., Margueron R., Rein- 
berg D., Green R., and Farnham P.J. 2004. Silencing of human polycomb target genes is associated with methylation of histone H3 Lys 27. Genes Dev. 18: 1592.

Kleer C.G., Cao Q., Varambally S., Shen R., Ota I., Tomlins S.A., Ghosh D., Sewalt R.G., Otte A.P., Hayes D.F., Sabel M.S., Livant D., Weiss S.J., Rubin M.A., and Chinnaiyan A.M. 2003. EZH2 is a marker of aggressive breast cancer and promotes neoplastic transformation of breast epithelial cells. Proc. Natl. Acad. Sci. 100: 11606.

Kohlmaier A., Savarese F., Lachner M., Martens J., Jenuwein T., and Wutz A. 2004. A chromosomal memory triggered by xist regulates histone methylation in $\mathrm{x}$ inactivation. PLoS Biol. 2: E171.

Krogan N.J., Kim M., Tong A., Golshani A., Cagney G., Canadien V., Richards D.P., Beattie B.K., Emili A., Boone C., Shilatifard A., Buratowski S., and Greenblatt J. 2003. Methylation of histone H3 by Set 2 in Saccharomyces cerevisiae is linked to transcriptional elongation by RNA polymerase II. Mol. Cell. Biol. 23: 4207.

Kubicek S. and Jenuwein T. 2004. A crack in histone lysine methylation. Cell 119: 903.

Kuzmichev A. and Reinberg D. 2001. Role of histone deacetylase complexes in the regulation of chromatin metabolism. Curr. Top. Microbiol. Immunol. 254: 35.

Kuzmichev A., Jenuwein T., Tempst P., and Reinberg D. 2004. Different EZH2-containing complexes target methylation of histone H1 or nucleosomal histone H3. Mol. Cell 14: 183.

Kuzmichev A., Nishioka K., Erdjument-Bromage H., Tempst P., and Reinberg D. 2002. Histone methyltransferase activity associated with a human multiprotein complex containing the Enhancer of Zeste protein. Genes Dev. 16: 2893.

Kuzmichev A., Margueron R., Vaquero A., Preissner T., Scher M., Kirmizis A., Ouyang X., Brockdorff N., Abate-Shen C., Farnham P.J., and Reinberg D. 2005. Composition and histone substrates of polycomb regressive group complexes change during cellular differentiation. Proc. Natl. Acad. Sci. 102: 1859 .

Laible G., Wolf A., Dorn R., Reuter G., Nislow C., Lebersorger A., Popkin D., Pillus L., and Jenuwein T. 1997. Mammalian homologues of the Polycomb-group gene Enhancer of zeste mediate gene silencing in Drosophila heterochromatin and at S. cerevisiae telomeres. EMBO J. 16: 3219.

Lund A.H. and van Lohuizen M. 2004. Polycomb complexes and silencing mechanisms. Curr. Opin. Cell Biol. 16: 239.

Ng H.H., Xu R.M., Zhang Y., and Struhl K. 2002. Ubiquitination of histone H2B by Rad6 is required for efficient Dot1mediated methylation of histone H3 lysine 79. J. Biol. Chem. 277: 34655.

Ng J., Hart C.M., Morgan K., and Simon J.A. 2000. A Drosophila ESC-E(Z) protein complex is distinct from other polycomb group complexes and contains covalently modified ESC. Mol. Cell. Biol. 20: 3069.

Nishioka K., Rice J.C., Sarma K., Erdjument-Bromage H., Werner J., Wang Y., Chuikov S., Valenzuela P., Tempst P., Steward R., Lis J.T., Allis C.D., and Reinberg D. 2002. PRSet7 is a nucleosome-specific methyltransferase that modifies lysine 20 of histone $\mathrm{H} 4$ and is associated with silent chromatin. Mol. Cell 9: 1201.

Pirrotta V. and Rastelli L. 1994. White gene expression, repressive chromatin domains, and homeotic gene regulation in
Drosophila. Bioessays 16: 549.

Rea S., Eisenhaber F., O'Carroll D., Strahl B.D., Sun Z.W., Schmid M., Opravil S., Mechtler K., Ponting C.P., Allis C.D., and Jenuwein T. 2000. Regulation of chromatin structure by site-specific histone H3 methyltransferases. Nature 406: 593.

Rice J.C., Nishioka K., Sarma K., Steward R., Reinberg D., and Allis C.D. 2002. Mitotic-specific methylation of histone H4 Lys 20 follows increased PR-Set7 expression and its localization to mitotic chromosomes. Genes Dev. 16: 2225.

Rosenberg M.I. and Parkhurst S.M. 2002. Drosophila Sir2 is required for heterochromatic silencing and by euchromatic Hairy/E(Spl) bHLH repressors in segmentation and sex determination. Cell 109: 447.

Schotta G., Lachner M., Sarma K., Ebert A., Sengupta R., Reuter G., Reinberg D., and Jenuwein T. 2004. A silencing pathway to induce $\mathrm{H} 3-\mathrm{K} 9$ and $\mathrm{H} 4-\mathrm{K} 20$ trimethylation at constitutive heterochromatin. Genes Dev. 18: 1251.

Shankaranarayana G.D., Motamedi M.R., Moazed D., and Grewal S.I. 2003. Sir2 regulates histone H3 lysine 9 methylation and heterochromatin assembly in fission yeast. Curr. Biol. 13: 1240.

Shao Z., Raible F., Mollaaghababa R., Guyon J.R., Wu C.T., Bender W., and Kingston R.E. 1999. Stabilization of chromatin structure by PRC1, a Polycomb complex. Cell 98: 37.

Silva J., Mak W., Zvetkova I., Appanah R., Nesterova T.B., Webster Z., Peters A.H., Jenuwein T., Otte A.P., and Brockdorff N. 2003. Establishment of histone h3 methylation on the inactive X chromosome requires transient recruitment of EedEnx1 polycomb group complexes. Dev. Cell 4: 481.

Sims R.J., III, Nishioka K., and Reinberg D. 2003. Histone lysine methylation: A signature for chromatin function. Trends Genet. 19: 629.

Sterner D.E. and Berger S.L. 2000. Acetylation of histones and transcription-related factors. Microbiol. Mol. Biol. Rev. 64: 435.

Struhl K. 1998. Histone acetylation and transcriptional regulatory mechanisms. Genes Dev. 12: 599.

Sun Z.W. and Allis C.D. 2002. Ubiquitination of histone H2B regulates $\mathrm{H} 3$ methylation and gene silencing in yeast. Nature 418: 104.

Taunton J., Hassig C.A., and Schreiber S.L. 1996. A mammalian histone deacetylase related to the yeast transcriptional regulator Rpd3p. Science 272: 408.

Vaquero A., Scher M., Lee D., Erdjument-Bromage H., Tempst P., and Reinberg D. 2004. Human SirT1 interacts with histone $\mathrm{H} 1$ and promotes formation of facultative heterochromatin. Mol. Cell 16: 93.

Varambally S., Dhanasekaran S.M., Zhou M., Barrette T.R., Kumar-Sinha C., Sanda M.G., Ghosh D., Pienta K.J., Sewalt R.G., Otte A.P., Rubin M.A., and Chinnaiyan A.M. 2002. The polycomb group protein EZH2 is involved in progression of prostate cancer. Nature 419: 624 .

Wood A., Krogan N.J., Dover J., Schneider J., Heidt J., Boateng M.A., Dean K., Golshani A., Zhang Y., Greenblatt J.F., Johnston M., and Shilatifard A. 2003. Bre1, an E3 ubiquitin ligase required for recruitment and substrate selection of Rad6 at a promoter. Mol. Cell 11: 267.

Zhang Y. and Reinberg D. 2001. Transcription regulation by histone methylation: Interplay between different covalent modifications of the core histone tails. Genes Dev. 15: 2343. 


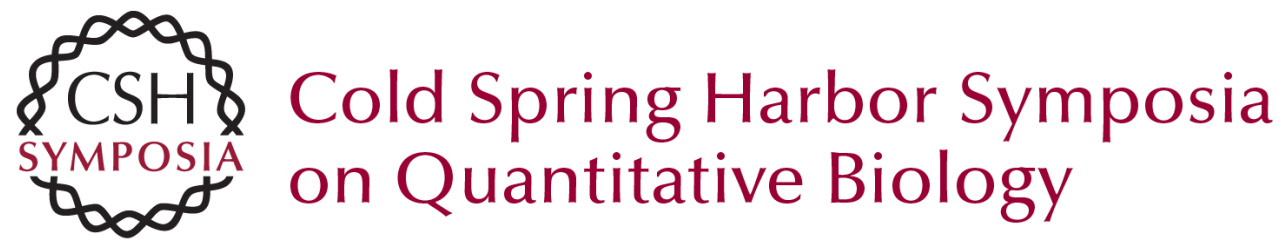

\section{Steps Toward Understanding the Inheritance of Repressive Methyl-Lysine Marks in Histones}

D. REINBERG, S. CHUIKOV, P. FARNHAM, et al.

Cold Spring Harb Symp Quant Biol 2004 69: 171-182

Access the most recent version at doi:10.1101/sqb.2004.69.171

References This article cites 42 articles, 19 of which can be accessed free at: http://symposium.cshlp.org/content/69/171.full.html\#ref-list-1

\section{License}

Email Alerting

Receive free email alerts when new articles cite this article - sign up in Service the box at the top right corner of the article or click here. 